\title{
Level of Academic Performance Among Faculty Members in the Context of Nepali Higher Educational Institution
}

\author{
Krishna Prasad Paudel $\mathrm{a}^{\mathrm{a}^{*}}$ \\ ${ }^{a}$ Kathmandu University, Nepal \\ *Correspondence: kpaudel.np@gmail.com
}

\begin{abstract}
Academic performance is taken as the process of carrying out academic activities and discourses by faculty members to enhance their academic activities and discourses. The purpose of this research was to identify the faculty member's level of academic performance in higher educational institutions. To conduct this research, a quantitative methodology was employed. The tools to measure the academic performance of faculty members were developed using Delphi method. The data were collected with 445 sampled respondents from four universities. The factor analysis was used to explore the dimensions of academic performance. The factor analysis identified four factors of academic performance i.e., research and publication, innovation, interactive learning, and capacity building. To analyze the level of academic performance, mean and the standard deviation was used. It was found that individual differences and the organizational environment, culture, and technological infrastructure were crucial to influence the pace and level academic performance in academia.
\end{abstract}

Keyword: academic performance, faculty member, intellectual capital, level, university

\section{INTRODUCTION}

This study identifies the level (low, medium, and high) of academic performance among faculty members in the universities of Nepal. In the context of higher education institutions, faculty members' academic activities and discourses to enhance their research, innovation, and capacity building process are considered as academic performance. Likewise, the level refers faculty members' degree of engagement in academic activities. The knowledge of individual and institutional supports to enhance academic activities in academia. Davenport and Prusak (1998) highlighted knowledge as "a dynamic perception, beliefs, thought regarding situational information from an expert perspective that provides an integrated framework and design for assessing, managing and incorporating information" (p. 5). These scholars also emphasize that knowledge is generated from the mind of an individual and is incorporated in relevant works. Knowledge often gets embedded in organizations in the form of documents or repositories and manages organizational practices, standards, routines, and processes. The working environment of academic institutions plays a vital role in enhancing faculty members' capability in both teaching-learning and research activities. According to Fives and Looney (2009), "teacher-efficacy has been identified as a critical construct in the process of teaching and research in academia" (p. 182). Furthermore, the efficacy of faculty members' beliefs can also affect their goals, motivation, ability, and perception in confronting the existing problems and challenges of academic institutions. The academic roles of faculty members in Higher

Received June 1, 2020; revised September 5, 2020; September 7, 2020; accepted November 1, 2020; electronically published May 1, 2021

Journal of Comparative \& International Higher Education

May, 2021, Vol. 13, No. 2, pp. 98-111.

DOI: $10.32674 /$ jcihe.v13i2.2450

(C) 2021 Journal of Comparative \& International Higher Education. All rights reserved. 
Education Institutions (HEIs) vary by their process of conducting academic activities and thought of academic discourses. Hence, universities conduct academic activities such as teaching, learning, conducting academic activities, workshops, and seminars along with the publication of research findings.

According to Steinberger (1993), academic performance is a multidimensional concept related to human growth and cognitive, emotional, social, and physical development. Likewise, Fairweather (1996) and Asif et al. (2017) explained academic performance as activities like teaching and research. In this line, Hazelkorn (2015) considered peer review and accreditation as faculty member's performance assessment in most of the higher education institutions. The achievement and performance of universities' vision, mission, and goals depend on the rigorous academic activities of faculty members. Faculty members' engagement in different academic activities also makes them competent which ultimately contributes to the university by making it more competitive in educational and research services.

Different studies highlighted teaching, learning, and research activities as the main key activities of faculty members in the context of a higher education. Elrehail et al. (2018) stated that innovation in higher education institutions is considered the ability to implement a new proactively reinforced organizational method, process, and product which has a significant effect on the activities of higher education institutions and their stakeholders. The study of Chiasson et al. (2015) shows that each faculty member is responsible for the quality and content of instruction in the classroom. In this regard, the working environment, including the sharing culture and the leadership of academic institutions, plays a vital role in enhancing the academic activities and discourses of faculty members in the higher education context.

Faculty members are expected to use their expertise and professional experience to serve their departments, their colleges, the university, the community, and their professions through service activities (Abes et al., 2002). The role of the faculty member at the school-level focuses more on teaching while in higher education institutions it focuses on mentorship and making the students involved in research activities. The past research highlighted that faculty members' engagement in academic activities helps to enhance the academic performance.

\section{PERFORMANCE OF HIGHER EDUCATION INSTITUTIONS}

The organizational strategy determines the expected performance of any institution. The strategic objectives are measured based on the performance of an institution (Rejc \& Zaman, 2012). In the academic context, the overall performance needs to align with academic and administrative activities. Hazelkorn (2015) found that the majority of higher education institutions use peer review, publications, and accreditation as their performance evaluation. HEIs ensure that students receive high-quality service in academic activities. Suryadi (2007) highlighted that HEIs have a responsibility to produce graduates that can accommodate challenges emerging in society, such as graduates producing high-quality profiles and competence in their respective professions. In the same line, Miller (2007) explained academic performance as academic status, classes of degree, and graduation rates. Likewise, Knapp et al. (2012) mentioned the job of HEIs to teach, research, and perform service. In the same way, Ahmed, Ismail, Amin, and Islam (2014) noted that high institutional support of teachers increased student satisfaction and academic performance. Todays' higher education institutions demand smaller class sizes, library resources such as scholarly journals, research and teaching assistants, grant writing support, and offering required training and faculty meetings in flexible delivery methods (Delello et al., 2018). The performance management literature advocates securing the effective implementation of the strategy of any organization. In an 
academic context, research-related and teaching-related performance evaluation system are highly prioritized (Cadez et al., 2017). Hence, scholars highlighted the activities of the higher education institutions as core administrative and academic activities.

\section{Academic Performance in Higher Educational Context}

Academic performance refers teaching and research activities (Ter Bogt \& Scapens, 2012). To be more competitive, research is more highly valued than teaching in academic institutions (Newman, 2008). The research activities of the faculty member carry the root cause of any issues to the society, so the publication of research is a widely accepted matric of academic performance. In contrast, publishing in low impact journals reduces the academic excellence of the researcher (Harvey et al., 2010). Hence, the teacher's effectiveness can be measured by the quality information inside the classroom, students' placement, the position of the employment of graduation, research carried out, and publication in the indexed journals in the context of higher education institutions. Universities are the key places to conduct academic activities such as teaching, learning, conducting academic activities, workshops, and seminars along with the publication of research findings. According to Steinberger (1993), academic performance is a multidimensional concept of academic activities and discourses related to the emotional, social, cognitive, and physical development of humans. The main objective of academic output is to prepare both faculty members and their students for research activities. Besides this, another objective is to prepare them for delivering the ideas and concepts of research inside a classroom along with developing new concepts. University Grants Commission (UGC) India (2010) identified the academic performance indicator (API) into three categories-(1) teaching and learning (2) co-curricular and professional development, and (3) research and academic activities. The framework highlights both activities of lecturing in classrooms and conducting research activities outside the classrooms. Research innovations inside as well as outside the classrooms help them to develop new knowledge. It further enhances the capacity of the individuals in the context of educational institutions. Asif et al. (2017) explain academic performance as activities like teaching and research. They focus on the academic performance of faculty members as their teaching inside classrooms and conducting research outside the classrooms. After teaching, the next job would be to conduct research activities which generate new concepts and enhance the capacity of both the students and faculty members. Hilman and Abubakar (2017) mention that academic performance is concerned with academic attainment and extra-curricular achievements of students. The researcher further explained the students' academic activities include the academic ranking, graduation classes, and graduation rates of students as indicators of university performance evaluation while the extra-curricular accomplishments consist of competitive roles, creativity, organizational strength, sustainability, and market share. In the line of Taylor (2007), most universities emphasize their dual mission of teaching and research. The major objectives of the university are to teach, make active participation of the learners along with the faculty members in the research activities, produce new knowledge which is required in the society and nation, and enhance the individuals' and organizational capacity. The faculty members' academic performance is associated with teaching, learning, research, publication, generation of new knowledge, and capability of solving problems in academia. The next section explains the teaching and learning activities in higher education institutions.

\section{Teaching and Learning}

The teaching performance of a faculty member is related to the classroom activities including information inside the classroom along with grades of the students, the number of degrees awarded 
graduates, and their job position (Ter Bogt \& Scapens, 2012). These performances of the faculty members are measured only at the organizational level. Therefore, the quality of education offered by individual teachers inside the classroom during teaching and interaction is dependent upon the implementation of those measures at the organizational level. Similarly, student perspectives and expectations also play an important role in determining their teaching quality in an academic setting (Bedggood \& Donovan, 2012). Hence, the organizational culture assists employees to share ideas and concepts among peers and coworkers. The knowledge-sharing culture in an organization is directly associated with leadership support and commitment. Likewise, Lin (200) highlighted that the extrinsic and intrinsic motivation of the individual matters in the knowledge sharing process in an institution. So, the influence of leadership has a remarkable role in knowledge sharing processes in any institution (Lee, Gillespie, Mann, \& Wearing, 2010). It further enhances the learning and mentorship capabilities of the employee of institutions. Teaching performance relates to the number of students, degrees awarded, and the quality of the education provided (Ter Bogt \& Scapens, 2012). Research-based performance evaluation in academia is detrimental to quality teaching (Kallio and Kallio, 2014). The teaching and learning activities in higher educational institutions are concerned with the capacity building of both faculty members and students through research activities.

\section{Research and Publication}

Researchers have emphasized the value of quality of research impact and the number of papers published in high-quality index journals to measure the performance of the academic staff in universities (Harvey et al., 2010). Bedggood and Donovan (2012), focuses on teaching quality, effectiveness, and student assessment as the performance of the faculty members in the academic world. We can say that the core business of a university is to teach and conduct research activities. In this regard, Schimank and Winnes (2000) explained the model of teaching and research in university as (i) pre-humboldtian model, which particularly focuses on teaching and research, (ii) the integration of research and teaching in an academic institution at the same time, and (iii) post-humboldtian pattern differentiation for teaching and research. Henningsen (2006) explained that "research is carried out separately from teaching and mentioned as scientific inquiry of a researcher" (p. 404). This scholar further argued that "the blending of teaching and research was declared as an important thought of scientific education" (Henningsen, 2006 p. 98). This showed that teaching along with research is the key activity of higher education.

Knowledge is the information stored in our minds. The information is either transferred to others or cannot be transferred. The element of knowledge can be explicit and tacit by its characteristics and nature (Chen \& Hung, 2010). The knowledge sharing attributes of individuals matters in the organization. These scholars further explain that tacit knowledge is the knowledge that is formed based on the concept and ideas of know-how and created through experiences of individuals and applied in both classroom and research process. Whereas explicit knowledge is the know-what knowledge and related with day-to-day tasks and jobs. Hence, the tacit explains the subjective phenomenon and the explicit refers to the objective nature of knowledge of the individual. Initially, the concepts of the tacit and explicit knowledge came in practice as the form of knowledge creation theory by Nonaka and Takeuchi (1995). Later, the perspectives of knowledge are carried in both business and academic worlds. In academic institutions, research is valued more highly than teaching (Newman, 2008). In academia, research is used to bring the individual concepts and ideas into products or in some context in the form of articles. 


\section{Academic Activities in Nepalese Universities}

Nepali higher education institutions play a significant role in the development of the nation's human capital and the economy in general, particularly after 1989. Investment in education from the private sector has provided more opportunities for Nepali than ever before to pursue higher education within the country. The Higher Education Policy by University Grants Commission Nepal (2015) emphasized: (i) to promote the access to higher education by regulating, managing and maintaining the dignity of the higher education institutions regarding its establishment, operation, regulation, and management, (ii) to develop human resource inclined to science and technology, competitive and enterprising for the overall socio-economic development having established higher education as cornerstones of original knowledge and identity considering extension and diversification of school education, and (iii) to make globally competitive citizens with due focus on relevance, usefulness, and quality that increases the opportunities for higher education and research. According to the National Educational Policy released by the Ministry of Education, Science, and Technology (MOEST, 2019), the goal of education is to develop human resources by making education competitive, techno-friendly, employment-oriented, and productive as per the need of the country. Hence, the education of Nepal demands highly capable graduates from university. The idea of research and publication is yet to be resituated and clearly understood as a productive instrument for socioeconomic, technological, and cultural progress through inquiry and inquiry-based teaching/learning (Bista et al., 2019). Nepali researchers have limited publications in peer-reviewed journals (Simkhada et al., 2014). Researchers highlighted that Nepali universities are in a growing phase to implement research activities as a regular activity of the institution. Universities are knowledge centers which aim to open academic and professional avenues for the students, parents, faculties, administrators, and other stakeholders (UGC Nepal, 2011). The policies of higher education highly prioritized research and capacity building in Nepal. It also emphasizes the development of human capital to enhance the intellectual capital of individuals and institutional.

\section{METHODOLOGY}

A quantitative methodology was used to conduct this research. The population of this study primarily comprises of all the teaching faculty of different schools/faculties of four different universities of Nepal. The survey tools were self-developed employing Delphi methods. The Delphi method is a popular process to achieve consensus on the important issues or complex social problems with the help of subject experts and practitioners in a particular field (Linstone \& Turoff, 2002). The Delphi technique is a method used for enabling a group of individuals to collectively address a complex problem through a structured group communication process (Hasson, Keeney, \& McKenna, 2000). The different steps followed in the Delphi process are (i) participation of first round of the questionnaire, (ii) selection and invitation of a panel discussion, (iii) collection and analysis of the completed questionnaire for the first round, (iv) feedback on the responses gathered from all participants, (v) presentation and analysis of second round of questionnaire, and (vi) iteration. The Delphi process takes place through several rounds of surveys that elicit panelists' opinions about the topic at hand (Geist, 2010). Delphi questionnaires are designed based on the problem at hand and emerge based on group input. Each round is based upon the results of the round before it. The surveys may be paper-based or electronic (Geist, 2010).

The Delphi process was carried out considering the local knowledge, norms, and values on the social context (Paudel, 2019). The Delphi process generally includes in-depth interviews with practitioners in the 
field (grounded), written interview, open-ended questions, and panel discussion with experts. The identified indicators from the grounded data, including experts' views and insights received from the panel discussion, were compared with literature and categorized into different dimensions of academic performance. Linstone and Turoff (2002) stated that the process might also vary depending on the complexity of the subject matter. For example, there may be one in-depth interview with few experts or several in-depth interviews with numerous experts representing different professional arenas. In my study, I applied all of the abovementioned steps of the Delphi technique to identify the dimensions of academic performance.

Identification of the research problem(s) is the first and most important step in the Delphi process (Keeney et al., 2011). To understand pressing research problem(s) and issues, I conducted in-depth interviews with practitioners and experts. During the interviews with experts, I collected information about factors that determine the academic activities of faculty members in a higher educational context. The indepth interview, literature, and written responses from the practitioners identified 26 items of academic performance under two dimensions of academic performance. Keeney et al. (2011) mentioned that if 70\% or more of the experts' panel agree on the importance of a statement, it is considered to have reached a consensus. In my case, I retained items having more than $70 \%$ of the total rating under strongly agree and agree categories. I removed items scoring less than 70\%. I invited experts, professionals, and practitioners for a panel discussion to provide their views on academic performance. As suggested by Linstone and Turoff (2002), I compared the indicators suggested from the grounded data, including experts' views and insights received from panel discussion, with literature and categorized these 23 items into two dimensions of academic performance (teaching \& learning and research \& publication).

The researcher developed 7-point Likert scales from the indicators identified from the field (grounded) expert interviews and literature to measure knowledge management practices. Croasmun and Ostrom (2011) argue that high scale points increase reliability. On that account, the researcher followed the 7-point scale to develop a questionnaire for this research. The validity and reliability of the tool was checked before collecting the data. Many statistical tools are available to measure the reliability and internal consistency of the data. Among them, the split-half method and alpha coefficient of consistency is mostly used (Best \& Kahn, 2006). Throughout my analysis, I used Cronbach's alpha-coefficient to test the instrument's accuracy. The internal reliability coefficient of the instrument is measured through the Cronbach's alpha $(\alpha)$ as at least 0.7 since all dimensions of academic performance are greater than 0.7 and satisfy this criterion (Santos, 1999). Creswell (2008) explained validity as to whether the questionnaire measures what it intends to measure or not. The construct, content, and criterion validity are three principal validities that need to be considered at the very outset in quantitative research (Huck, 2012; Cohen Manion, \& Morrison, 2018).

Developing research questions, hypotheses, and research tools need to align with the research problem and articulating their interconnection and association enhances construct validity (Mohajan, 2017). Explaining the concept of social construct clearly and breaking the abstract concept into different underlying dimensions and measurable items improve construct validity. The Delphi method, a rigorous process of constructing tools ensured content validity. It was further supplemented by literature review and field interaction with faculty members and experts. The content validity is further validated through the factors and items of the particular factor/dimension. Mohajan (2017) stated that the content validity checks whether various items of the questionnaire have covered all the aspects of the study. For content validity, I reviewed all the relevant literature and obtained advice from the subject experts and the practitioners to make sure that all the variables to measure the concept in question were included. Moreover, the researcher 
applied the Delphi technique while developing questionnaires, which incorporated the contextual experience of practitioners and experts in a particular field. Criterion validity is further categorized as concurrent validity and predictive validity (Schutt, 2014). The concurrent validity refers to a test's ability to predict an occurrence in its present form (Drost, 2011). The concurrent validity addresses and supports research by adopting and applying the same tools developed by the Delphi method.

I administered the constructed tools before finalizing the questionnaire among the faculty members of different universities. The pilot survey was done to obtain estimates about expected response rates, data quality, validity and comprehensibility of the questionnaire (Silman \& Macfarlane, 2001). Different researchers mentioned that near about $10 \%$ sample was needed from the total number of the final sample to estimate the reliability of the scale (Lackey \& Wingate, 1998; Hertzog, 2008). Thus, I took 49 sample respondents while conducting the pilot test and established the internal reliability of this scale. Almost 11 percent of the total sample students participated in the pilot. Those faculty members were not included in the survey study. These scales were administered among those faculty members of the university who were not involved as the sample respondents for the study. From the observation of the pilot study, no serious issue was found. This study confirmed that the main study was feasible to complete within a given period. Furthermore, the pilot study ensured that the survey through a questionnaire was appropriate to address research problems and research questions of the study.

The data was collected from 445 faculty members of higher education institutions of Nepal. The data was collected through stratified sampling methods. The respondents were taken from the four different departments, Faculty of Arts, Education, Management, and Science of the four universities who work in

the centrally located colleges of such universities. So, it was strata of a relevant university and later the sample was selected through a random sampling process. Initially, the data was coded in SPSS version 25. The factor analysis was used to identify the dimensions of academic performance. Analysis of the factor is a multivariate statistical method which was used to identify and explore the concerned items and variables in a group called factors (Rummel, 1967; Shenoy \& Madan, 1994). The factor analysis loaded 16 items of academic performance under four dimensions. For identifying the level of academic performance, I categorized the mean score by using the formula of Best's (1977, as cited in Shabbir et al., 2014) criteria as follows:

$$
\frac{\text { Higherscore }- \text { Lowerscore }}{\text { NumberofLevels }}=\frac{7-1}{3}=\frac{6}{3}=2
$$

The levels are categorized as high, medium, and low. These levels were calculated mainly based on the faculty members' mean score of $1-2.99,3-4.99$, and $5-7$ as low, medium, and high respectively.

\section{LEVEL OF ACADEMIC PERFORMANCE AMONG FACULTY MEMBERS}

The factor analysis was used to identify the dimensions of academic performance. The factor analysis explored four dimensions of academic performance such as research and publication, innovation, interactive learning, and capacity building in this study. The level of academic performance was then measured by combining the values of each dimension. The academic performances are presented in the form of research and publication, innovation, interactive learning, and capacity building. The level of dimensions of academic performance was measured by using mean and standard deviation. The findings of the statistical analysis are presented in Table 1 . Table 1 shows that overall academic performance including 
the dimensions of academic performance research and publication, innovation, and interactive learning is high. But in case of capacity building the level of academic performance is medium.

Table 1

Level of Academic Performance

\begin{tabular}{lccc}
\hline Dimensions & Mean & SD & Level of AP \\
\hline Research and Publication & 5.80 & 0.76 & High \\
Innovation & 5.74 & 0.95 & High \\
Interactive Learning & 5.79 & 0.86 & High \\
Capacity Building & 4.93 & 1.20 & Medium \\
Academic Performance & 5.56 & 0.72 & High \\
\hline
\end{tabular}

Note. $\mathrm{AP}=$ Academic Performance, $\mathrm{SD}=$ Standard Deviation

Table 2 explains the frequencies of academic performance among faculty members of higher education institutions in Nepal. The majority of the respondents pose a high level of academic performance in universities. The academic performance is the sum of the mean score of four dimensions (research and publication, innovation, interactive learning, and capacity building) in this study. A study conducted by Paez-Logreira et al. (2016) unveiled that the commitment of organization is changing in the global context which makes differences in the level of dimensions of academic performance. The knowledge creation process takes place in e-learning and web-based environments and this impact academic activities in academia (Syed Mustapha et al., 2017). So, due to the technological environment of the institution, it makes differences in managing and accessing the different academic activities and discourses by the faculty member in the higher educational institution.

Table 2

Description of Academic Performance Level

\begin{tabular}{lcccccccc}
\hline \multirow{2}{*}{ Dimensions } & \multicolumn{2}{c}{ High } & \multicolumn{2}{c}{ Medium } & \multicolumn{2}{c}{ Low } & \multicolumn{2}{c}{ Total } \\
\cline { 2 - 9 } & $\mathrm{N}$ & $\%$ & $\mathrm{~N}$ & $\%$ & $\mathrm{~N}$ & $\%$ & $\mathrm{~N}$ & $\%$ \\
\hline Research and Publication & 365 & 82.0 & 78 & 17.5 & 2 & 0.5 & 445 & 100 \\
\hline Innovation & 364 & 81.8 & 76 & 17.1 & 5 & 1.1 & 445 & 100 \\
\hline Interactive Learning & 346 & 77.8 & 96 & 21.6 & 3 & 0.6 & 445 & 100 \\
\hline Capacity Building & 193 & 43.4 & 217 & 48.8 & 35 & 7.8 & 445 & 100 \\
\hline Academic Performance & 341 & 76.6 & 103 & 23.2 & 1 & 0.2 & 445 & 100 \\
\hline
\end{tabular}

Note. $\mathrm{N}=$ Number of Respondent, $\%=$ Percentage for a particular number

The majority of the respondents had high academic performance in all dimensions except capacity building. The result shows that very few respondents have the low level of academic performance. The result shows that the practices of the faculty member of HEIs are participating regularly to enhance their academic excellence except for the capacity building processes. The growing demands of society can be fulfilled only by conducting projects and carrying out the findings to the society as a product of knowledge as intellectual capital (Wiig, 1993). The intellectual capital can be enhanced through practices of academic activities and discourses. The innovation combined new ideas, thought, and concepts to produce new knowledge in academia (Manhart \& Thalmann, 2015). So, it demands learning environment and innovative ideas to succeed in the organizational goal. 


\section{FINDING AND DISCUSSION}

The factor analysis identified the four factors of the academic performance of the faculty members as research and publication, innovation, interactive learning, and capacity building. The first factor, research and publication, indicated most activities of research in academia by the faculty members. The second factor showed the innovative processes and activities of the faculty members. The third factor explained the interactive learning process and the fourth factor showed the activities of the faculty member to enhance the capacity building at the individual level. The quality level in education is one of the major concerns of government leaders, politicians, academics, and researchers (Fialho et al., 2010). The organizational success or failure will be decided by the degree of direction through the pinnacle administration. The evolving approach focuses on the social dynamics between organizational members and the complexity of day-to-day tasks; the engineering method focuses on management strategies to promote awareness of the transition that is necessary for capacity enhancement (Van den Hooff \& Huysman, 2009). Through knowhow sharing, development, codification, and incorporation of explicit and tacit knowledge, leaders play a necessary function in including value to business processes (Nonaka \& Takeuchi, 1995). Organizational lifestyle, on the other hand, is another essential thing which contributes to knowledge development and leverage.

The involvement in research is kept as a necessary academic performance indicator to be a good faculty member of the university to increases the level of individual academic discourses. Here the level of academic performance of the faculty member of higher education institutions is categorized as low, medium, and high. Research results on education quality show a positive relationship between student's academic performance and teaching quality (Fialho et al., 2010). The overall academic performance including the dimensions of academic performance, research and publication, innovation, and interactive learning is high. But in the case of capacity building, the level of academic performance is medium. The pace of capacity building shows in the level of medium. This may be the cause of low access to technology and low rate of research activities in the context of the higher education institution.

The research and publication dimensions are determined by the different activities conducted by the faculty member in HEIs. The different activities include involvement in research activities, bringing of research in classroom, mentoring through technology, converting theory in practice, interaction with students, and publication of the academic activities in the different journals. Likewise, the innovation dimension is comprised of worthy information inside classroom, case base learning, environment of the classroom, and focuses on academic activities. For interactive learning, it includes preparation of lesson plan, usage of e-portal, and dissemination of the information based on the lesson plan. In case of capacity building, it includes generation of new knowledge, involvement of students to the research activities, and technology in the classroom.

A lot of research suggests that factors influencing teachers to engage in research activities are the demand of this century. Advanced information is improved and disseminated through research (Levin, Cooper \& MacMillan, 2011). In this context, the research award and the conduction of research activities are the key concerns to prepare and publish article as academic activities in academic world. Cadez et al. (2017) illustrated the research-based output comparison in academia that determined the faculty member's exceptional teaching. According to Ebersberger and Altman (2013), universities face challenges of high expectations from stakeholders, global competition, and technological advances. Suciu et al. (2013) considered that universities are centers for knowledge creation to promote knowledge retrieval using 
appropriate tools and technologies. In this context, leadership determines the practices of academic activities and discourses regarding the nature of knowledge sought and created in academia (Al Saifim et al., 2016). The cycle of information development in academic institutions also exists in the e-learning process and web-based environments which affects academic activities (Samoila et al., 2014; Syed Mustapha et al., 2017). Consequently, the efficiency of faculty members increases and a higher level of productivity is achieved (Laloux, 2014). Leadership plays an integral role in designing, improving and maintaining organizational skills with the support of the wonderful groups within a large number of staff (Chawla \& Joshi, 2010). The academic institution plays a vital role to strengthen the overall development of the nation through the production of human capital. The role of the institution's head and policy adopted by the academic institution is important to the human capital development process.

In the situation of the pandemic, the pedagogy of teaching and learning is changed and mostly focused on instructional methods through technological tools (Brown et al., 2020). A growing number of reports document that universities striving for government funding, research grants, and high rankings have adopted strategies including recruitment and reward systems that favor academics with top publications or the potential to secure such publications (Cadez et al., 2017). In these days, facts of publications, citations per article, and research are awarded to the institution to rank public universities. Hence, the finding showed by this study emphasizes the rigorous engagement in the academic activities and discourses to maximize the research collaboration by the higher educational institutions.

\section{CONCLUSION}

This study identified a considerably high level of academic performance among faculty members of higher education institutions of Nepal. The pace of academic performance of faculty members of HEIs seems high except capacity building. The learning behavior, network building, and assessment capacity of faculty members varies to each other to enhance their capacity building processes, to produce new knowledge, and to become more innovative. The academic performance of faculty members in higher education institutions are concerned with improved practices of academic activities and discourses. The findings indicate that HEIs need to emphasize greater attention to the key processes and activities of academic activities to enhance the knowledge economy of the nation.

\footnotetext{
Krishna Prasad Paudel, Ph.D., is a visiting faculty of Kathmandu University School of Education. As a quantitative researcher, his research interest includes financing of education, educational leadership, management information systems in educational institutions, and knowledge management. Some of his current research projects include digital governance, educational policies in Nepal in the changing global context, and GESI audit in LGs of Nepal. Together with his research interest in knowledge management, he is working as Information and Communication Technology (ICT) policy maker. He worked at the Supreme Court of Nepal with the capacity of Information Technology (IT) Director, where he developed and implemented the ICT Master plan of the judiciary to automate judicial activities. It included both judicial case processing and court administration. Also, he has contributed to various Ministries and institutions of the Government of Nepal to develop the MIS System and deploy it.
} 


\section{REFERENCES}

Abes, E. S., Jackson, G., \& Jones, S. R. (2002). Factors that motivate and deter faculty use of servicelearning. Michigan Journal of Community Service Learning, 9(1).

Ahmed, I., Ismail, W. K. W., Amin, S. M., \& Islam, T. (2014). Institutional and faculty role in academic achievements of students: evidence from a public sector university of Pakistan. International Journal of Management in Education, 8(4), 419-431. doi: 10.1504/IJMIE.2014.064957

Al Saifi, S., Dillon, S., \& McQueen, R. (2016). The relationship between management support and knowledge sharing: An exploratory study of manufacturing firms. Knowledge and Process Management, 23(2), 124-135.

Asif, R., Merceron, A., Ali, S. A., \& Haider, N. G. (2017). Analyzing undergraduate students' performance using educational data mining. Computers and Education, 113, 177-194. doi: 10.1016/j.compedu.2017.05.007

Bedggood, R. E., \& Donovan, J. D. (2012). University performance evaluations: what are we really measuring? Studies in Higher Education, 37(7), 825-842.

Best, J. W., \& Kahn, J. V. (2006). Research in education (10th ed.). Pearson Education.

Bista, K., Sharma, S., \& Raby, R. L. (2019). 1 Telling stories, generating perspectives. Higher Education in Nepal: Policies and Perspectives, 1 .

Brown, N., Te Riele, K., Shelley, B., \& Woodroffe, J. (2020). Learning at home during COVID-19: Effects on vulnerable young Australians. Peter Underwood Centre for Educational Attainment.

Cadez, S., Dimovski, V., \& Zaman Groff, M. (2017). Research, teaching and performance evaluation in academia: the salience of quality. Studies in Higher Education, 42(8), 1455-1473. doi: 10.1080/03075079.2015.1104659

Chawla, D., \& Joshi, H. (2010). Knowledge management practices in Indian industries a comparative study. Journal of Knowledge Management, 14(5),708-725.

Chen, C. J., \& Hung, S. W. (2010). To give or to receive? Factors influencing members' knowledge sharing and community promotion in professional virtual communities. Information \& Management, 47(4), 226-236.

Chiasson, K., Terras, K., \& Smart, K. (2015). Faculty perceptions of moving a face-to-face course to online instruction. Journal of College Teaching \& Learning (TLC), 12(3), 321-240.

Cohen, L., Manion, L., \& Morrison, K. (2018). Research methods in education (8th ed.). Routledge Falmer.

Creswell, J. W. (2008). Educational research: Planning, conducting and evaluating quantitative and qualitative research. Pearson.

Croasmun, J., \& Ostrom, L. (2011). Using Likert-type scales in the social sciences. Journal of Adult Education, 40(1), $19-22$.

Davenport, T. H. \&Prusak, L. (1998). Working knowledge: How organisations manage what they know. HBS Press.

Delello, J. A., McWhorter, R. R., \& Marmion, S. L. (2018). Understanding the productivity of faculty members in higher education. International Journal of Management in Education,12(2), 154-178. doi: 10.1504/IJMIE.2018.10009661

Drost, E. A. (2011). Validity and reliability in social science research. Education Research and Perspectives, 38(1), 105-124.

Ebersberger, B., \& Altman, A. (2013). Universities in change: Managing higher education institutions in the age of globalization. Springer-Verlag.

Elrehail, H., Emeagwali, O. L., Alsaad, A., \& Alzghoul, A. (2018). The impact of transformational and authentic leadership on innovation in higher education: The contingent role of knowledge sharing. Telematics and Informatics, 35(1), 55-67. doi:10.1016/j.tele.2017.09.018

Fairweather, J. (2002). The mythologies of faculty productivity: Implications for institutional policy and decision making. The Journal of Higher Education, 73(1), 26-48. 
Fialho, I., Saragoça, J., Rebelo, H., Cid, M., Oliveira, M., Bonito, J., ... \& Trindade, V. (2010). Academic Performance in Public Higher Education Institutions: A study on the effects of Teacher Commitment, Teaching Methodologies and Evaluation Methodologies in Students attending Nursing and Management courses.

Fives, M., \& Looney, L. (2009). College instructors' sense of teaching and collective efficacy. International Journal of Teaching in Higher Education, 20(2), 182-191.

Geist, M. R. (2010). Using the Delphi method to engage stakeholders: A comparison of two studies. Evaluation and Program Planning, 33(2), 147-154.

Harvey, C., Kelly, A., Morris, H., \&Rowlinson, M. (2010). The Association of Business Schools. Academic Journal Quality Guide, 4.

Hasson, F., Keeney, S., \& McKenna, H. (2000). Research guidelines for the Delphi survey technique. Journal of Advanced Nursing, 32(4), 1008-1015.

Hazelkorn, E. (2015). Rankings and the reshaping of higher education: The battle for world-class excellence. Springer.

Henningsen, B. (2006). A joyful good-bye to Wilhelm von Humboldt: The German university and the Humboldtian ideals of "Einsamkeit and Freiheit". In The European Research University (pp. 91-107). Palgrave Macmillan.

Hertzog, A. M. (2008). Considerations in determining sample size for pilot studies. Research in Nursing \& Health, 13(2), 180-191. doi: 10.1002/nur.20247

Hilman, H., \& Abubakar, A. (2017). Strategic talent management and university performance: A theoretical perspective. European Journal of Business and Management, 9(4), 35-40.

Huck, S. W. (2012). Reading statistics and research (6th ed.). Pearson

Kallio, K. M., \& Kallio, T. J. (2014). Management-by-results and performance measurement in universitiesimplications for work motivation. Studies in Higher Education, 39(4), 574-589. doi: 10.1080/03075079.2012.709497

Keeney, S., Hasson, F., \& McKenna, H. (2011). The Delphi technique in nursing and health research. John Willey and Sons.

Knapp, L. G., Kelly-Reid, J. E., \&Ginder, S. A. (2012). Employees in Postsecondary Institutions, Fall 2011 and Student Financial Aid, Academic Year 2010-11: First Look (Provisional Data). NCES 2012-156rev. National Center for Education Statistics.

Lackey, N. R., \& Wingate, A. L. (1998). The pilot study: One key to research success. Advanced Design in Nursing Research, 2, 375-387.

Laloux, F. (2014). Reinventing organizations: A guide to creating organizations inspired by the next stage in human consciousness. Nelson Parker.

Lee, P., Gillespie, N., Mann, L., \& Wearing, A. (2010). Leadership and trust: Their effect on knowledge sharing and team performance. Management Learning, 41(4), 473-491.

Levin, B., Cooper, A., \& MacMillan, R. (2011, May). The Ontario knowledge network for applied education research [Paper presentation]. Canadian Society for the Study of Education, Fredericton, NB, Canada.

Lin, C. P. (2007). To share or not to share: Modelling tacit knowledge sharing, its mediators and antecedents. Journal of Business Ethics, 70(4), 411-28.

Linstone, H. A., \& Turoff, M. (Eds.). (2002). The Delphi method: Techniques and applications. Addison-Wesley.

Manhart, M., \& Thalmann, S. (2015). Protecting organizational knowledge: a structured literature review. Journal of Knowledge Management.

Miller, B. A. (2007). Assessing organizational performance in higher education. Jossey-Bass.

Ministry of Education, Science and Technology. (2019). National educational policy. Kathmandu: Author.

Mohajan, H. K. (2017). Two criteria for good measurements in research: Validity and reliability. Annals of SpiruHaret University. Economic Series, 17(4), 59-82. doi:10.26458/1746

Newman, M. (2008). Leeds rewards publication in top journals with bonus research time. Times Higher Education.

Nonaka, I., \& Takeuchi, H. (1995). The knowledge creating company. Oxford University Press. 
Paez-Logreira, H., Zamora-Musa, R., \& VelezZapata, J. (2016). Relation analysis of knowledge management, research, and innovation in university research groups. Journal of Technology Management \& Innovation, 11(4), 5-11. doi:10.4067/S0718-27242016000400002

Paudel, K. P. (2019). Constructing scale on knowledge management: Appreciating standard or self-constructed tools? International Journal of Interdisciplinary Studies, Crossing the Border, 7(2), 32-43.

Rejc, B. A., \& Zaman, G. M. (2012). Contemporary performance measurement systems in Central and Eastern Europe. Journal for East European Management Studies, 17(1), 69-103.

Rummel, R. J. (1967). Understanding factor analysis. Journal of Conflict Resolution, 11(4), 444-480. doi: $10.1177 / 002200276701100405$

Samoila, C., Ursutiu, D., \&Jinga, V. (2014). International conference on Interactive Collaborative Learning (ICL): The position of the remote experiment in the experiential learning and SECI

Santos, J. R. A. (1999). Cronbach's alpha: A tool of assessing the reliability scales. Journal of Extension, 37(2), 1-5. Retrieved from http://www.joe.org/joe/1999april/tt3.html

Schimank, U., \&Winnes, M. (2000). Beyond Humboldt? The relationship between teaching and research in European university systems. Science and Public Policy, 27, 397-408.

Schutt, R. K. (2014). Investigating the social world: The process and practice of research. Sage Publications.

Shabbir, M., Wei, S., Nabi, G., Zaheer, A. N., \& Khan, H. (2014). Job satisfaction status of public primary school teachers: A case of Pakistan administrative Kashmir. European Journal of Education Sciences, 1(4), 56-71. Retrieved from http://ejes.eu/wp-content/uploads/2017/01/1-4-6.pdf

Shenoy, G. V., \& Madan, P. (1994). Statistical methods in business and social sciences. Inter-India.

Silman, A., \& Macfarlane, G. (2001). Epidemilogical studies (2nd ed.). Cambridge.

Simkhada, P., Van Teijlingen, E., Devkota, B., Pathak, S. R., \&Sathian, B. (2014). Accessing research literature: A mixed-method study of academics in Higher Education Institutions in Nepal. Nepal Journal of Epidemiology, 4(4), 405-14.

Steinberger, E. D. (1993). Improving student achievement. American Association of School Administrators.

Suciu, M., Schebesch, K. B., Grigore, C., Busoi, M., Spiridon, R., \&Serbu, V. (2013). Universities as knowledge creation and sharing institutions: Research perspectives from Romania. Retrieved from https://mpra.ub.unimuenchen.de/20321/1/MPRA_paper_20321.pdf

Suryadi K. (2007). Framework of measuring key performance indicators for decision support in higher education institution. Journal of Applied Sciences Research, 3(12), 1689-1695.

Syed Mustapha, S. M. F. D., Sayed, B. T., \& Mohamad, R. (2017). Measuring process Innovation on double-flanked conceptual model for knowledge sharing on online learning environments. Journal of Theoretical and Applied Information Technology, 95(7), 499-1509.

Taylor, J. (2007). The teaching: research nexus: a model for institutional management. Higher Education, 54(6), 867884. doi: 10.1007/s10734-006-9029-1

Ter Bogt, H. J., \&Scapens, R. W. (2012). Performance management in universities: Effects of the transition to more quantitative measurement systems. European Accounting Review, 21(3), 451-497.

University Grants Commission, India. (2010). Regulations on minimum qualifications for appointment of teachers and other academic staff in universities and colleges and measures for the maintenance of standards in higher education.

University Grants Commission, Nepal. (2011). Reform in university system in the changing context. Kathmandu: Author.

University Grants Commission, Nepal. (2015). Higher education policy. Kathmandu: Author.

Van den Hooff, B., \&Huysman, M. (2009). Managing knowledge sharing: Emergent and engineering approaches. Information \& Management, 46, 1-9.

Wiig, K. M. (1993). Knowledge management methods: Practical approaches to managing knowledge. Schreiner Press. 